\title{
FUNDAMENTAL PERIOD AND DAMPING OF EXPERIMENTALLY TESTED REINFORCED-CONCRETE BUILDING UNDER DIFFERENT DAMAGE LEVELS
}

\author{
Adriana Cerovečki ${ }^{1}$ - Ivan Kraus ${ }^{1^{*}}$ \\ ${ }^{1}$ Department of Materials and Structures, Faculty of Civil Engineering Osijek, Josip Juraj Strossmayer University of \\ Osijek, Vladimira Preloga 3, 31000 Osijek, Croatia
}

\begin{tabular}{l}
\hline ARTICLE INFO \\
\hline Article history: \\
Received: 30.10 .2017$. \\
Received in revised form: 08.05.2018. \\
Accepted: 08.05.2018. \\
\hline Keywords: \\
Experiment \\
Shaking table \\
Damping \\
Fundamental period \\
Reinforced-concrete \\
Damaged building \\
\hline DOI: $h$ itpildoi.g/10.30765/er.39.111
\end{tabular}

DOI: http://doi.org/10.30765/er.39.1.11

\section{Introduction}

To blind predict the inelastic dynamic behavior of an experimentally tested structure using numerical

\begin{abstract}
:
Blind prediction of the dynamic behavior of experimentally tested structures employing numerical models is a professional and academic challenge that brings to test existing knowledge and produces a new understanding of the performance of structures. The pre-test model is usually first validated through the fundamental period. This only adds certainty to the elastic model. However, the post-elastic behavior is steered by damping inter alia. This property of the model is usually assessed based on empirically derived analytical expressions. This paper investigates to what extend analytical expressions for estimation of the fundamental period and damping give a good prediction of numerically and experimentally obtained counterparts. As a governing vehicle of this paper, experimentally obtained data from the 2012 blind test contest was used. The experiment included testing of a reinforced concrete frame using a shaking table and motions of increasing intensity levels, wherein the frame was not repaired between the tests. Besides the literature overview of analytical expressions for estimation of fundamental period and damping, this paper presents dynamic properties of experimentally tested building obtained from pseudo-free vibrations. The results of this study convey that analytical expressions underestimate experimentally and numerically obtained fundamental period, but give a good prediction of damping.
\end{abstract}

model is a demanding task. Among many decisions and estimates, selection of correct material properties, appropriate distribution of structural stiffness and mass, also the preparation of input

\footnotetext{
* Corresponding author. Tel.: +38531544678; fax: +38531540071

E-mail address: ikraus@gfos.hr
} 
motion are just a few of the many crucial steps that a numerical modeler needs to make when crafting a virtual structure. In addition, when modeling a structure subjected to strong-motion inputs dissipation of energy needs to be introduced duly and rationally. Lastly, the validity of a numerical model needs to be checked against similar models or by using analytical expressions. For instance, the first check is usually related to the first natural period of oscillation, or fundamental period for short. However, the model can be finally validated and calibrated only after the post-test results are publically announced. There are many expressions in the literature that allow evaluation of the fundamental period for different kinds of structures. However, research carried out within this work is focused on reinforced concrete structures. HadzimaNyarko et al. [1] demonstrated that European and American coded analytical expressions for estimation of fundamental periods overshoot the counterparts computed using numerical models for more than $80 \%$. This study was conveyed on a set of 480 different reinforced concrete buildings with shear walls dominant systems, systems that are the main component of earthquake-resistant buildings [2]. Draganić et al. [3] conducted a similar study on a set comprising reinforced concrete frame buildings. This study demonstrated that analytical expressions underestimate the fundamental period of single- to three-storey buildings by a factor of 3 when compared to the counterparts obtained from numerical models. Misestimating of the fundamental period can result in the underestimation of seismic forces for design or retrofitting [4]-[6]. Besides, a numerical model representing real experimentally tested structure with erroneously fundamental period prescribed cannot correctly forecast its inelastic behavior. Moreover, one has to bear in mind that the fundamental period can shift during strong earthquakes [7]. Such a shift can result in the change of structural behavior. Finally, this raises the question on how the structural damage affects the magnitude of fundamental period. Thus one of the objectives of this research was to shed new light on the changes of structural dynamic properties due to damage development. Under the same spotlight is damping in structures that is usually described in an idealized manner. Namely, in numerical models damping is usually embedded through a single numerical quantity. However, this single quantity needs to be able to capture several mechanisms that happen in vibrating structure: internal and contact friction, opening and closing of cracks, and thermal effects inter alia. Damping is usually estimated from data recorded on real structures undergoing microtremors [5]. However, it is clear that structural elements subjected to strong ground motions will crack severely and that friction in critical cracked regions can be higher than predicted in the design process. This opens another question. Does the damping in structure damaged by earthquakes change and by how much? Chopra [6] agrees that damping determined from structural motions that are small are not representative of the larger damping expected at higher amplitudes of structural motions. In the following chapters, a brief overview of expressions for estimation of the fundamental period and damping is made. As a governing vehicle for this paper, experimentally obtained data during the blind test challenge that took place in Lisbon, Portugal in 2012 was used. The experiment included a 3D reinforced concrete frame that was tested on a shaking table using four input motions of increasing intensity levels. The experimentally tested frame was used here to challenge the hypothesis that fundamental period and damping can reliably be determined from data recorded on damaged building subjected to diminishing forced vibrations. It was assumed that early stage strong input vibrations introduce a large amount of energy to the building with most of the mass concentrated at a single level so that it oscillates predominantly freely while the input vibrations diminish. Dynamic properties of the experimentally tested frame were derived after each of the four input motions. This provided insight on how fundamental period and damping change with damage accumulated in the building. The following chapters give a brief literature overview of analytical expressions for estimation of dynamic properties of buildings and comparison of their results with the results obtained from the experiment and the results obtained numerically. Finally, the conclusion and suggestions for further research are provided.

\section{Existing knowledge on fundamental period and damping forecast and quantities}

This chapter deals with expressions for estimation of the fundamental period and damping but also 
with prescribed and recommended damping quantities.

\subsection{Fundamental period estimation in design codes and from experiments}

Starting from the European code for seismic design of buildings [4] the following expression is proposed for estimation of the fundamental period:

$$
T_{1}=C_{t} \cdot H^{0,75}
$$

where $C_{t}$ is the coefficient depending on the type of building and $H$ is the height of the building in meters. The prescribed value of the coefficient for the reinforced concrete frame structures in Eurocode is 0,075 . The same expression, with $C_{\mathrm{t}}$ equal to 0,075 is also used in US and Canadian codes [8]. Value for $C_{t}$ is derived from data obtained from a building stock during eight earthquakes that shook California from early 1970's to the middle 1990's [8], [9]. Thus, it can be argued that the value of 0,075 is not valid for reinforced concrete structures in other earthquake prone areas due to different style and technology of construction, but also geomorphological conditions inter alia. The following expression includes more information regarding the structure, specifically, it includes the mass and stiffness of the structure [5], [9]:

$$
T_{1}=2 \cdot \pi \cdot \sqrt{\frac{m}{k}}
$$

where $m$ is the mass of the structure and $k$ is its lateral stiffness. Although this formula does not include an extensive amount of calculations it requires ample amount of time to calculate the stiffness of all vertical structural elements. Many researchers put their effort in finding simpler expression for estimation of fundamental period. Generally, studies correlate resonant period with the building height (e.g. [8]-[11]). Gallipoli et al. [11] conducted an extensive study and obtained an expression for estimation of the fundamental period based on measurements carried out on 250 reinforced concrete buildings in Europe:

$$
T_{1}=0,016 \cdot H
$$

When comparing results obtained using expressions (1) and (3) the latter one provides values smaller than the former one. The reason for that can be found in the magnitude of vibrations to which the buildings were excited. Namely, the structures or the soil could undergo plastic deformations during the Californian earthquake and thus return spuriously and unduly high fundamental periods. Clearly, a decrease in rigidity leads to an increase in the fundamental period. This is also confirmed by others (e.g. [10]). A group of authors [10] conducted a detailed study on the seismic response of buildings in the capital city of Lebanon using ambient vibration method. In addition, they summarized expressions for estimation of the fundamental period from world codes and other available literature. According to [10], the US code proposes the use of the following expressions for the estimation of the fundamental period of reinforced concrete frames:

$$
T_{1}=N / 10
$$

where $N$ represents number of floors. This expression generally associated with the term "rule of thumb" is considered [9] to provide a reasonably accurate estimation. However, other similar simple linear expressions can be found in the literature. A previous study [10] has documented a research that took place in Peru resulting in the following expression for buildings with less than five floors regardless of the year of construction:

$$
T_{1}=N / 24
$$

and expression for buildings with more than 5 floors, but built before 1974:

$$
T_{1}=N / 15
$$

However, they added that the expression (5) is valid also for buildings with more than 5 floors, but built after 1974. According to [10] expression (5) can be used for estimation of the fundamental period of buildings on rock sites. Thus this expression can provide a good estimation of the fundamental period of reinforced concrete structures tested on shaking tables with rigid platforms. Guler, K., et al. [12] derived the following expression for estimation of the fundamental period: 


$$
T_{1}=0,026 \cdot H^{0,9}
$$

where $H$ is the height of the reinforced concrete frame. This expression is based on measurements obtained on the real building and from numerical analyses of the same building. Recent study highlights [9] two more expressions for estimation of the fundamental period of oscillation, where the following one concerns reinforced concrete frames at first yield:

$$
T_{1}=0,0466 \cdot H^{0,9}
$$

while the next one, empirically derived expression, concerns reinforced concrete frames in general:

$$
T_{1}=0,0294 \cdot H^{0,804}
$$

The expression (9) was obtained by subtracting one standard deviation from the best-fit curve [9]. This was done to offer more reliable and conservative seismic design forces. Interestingly, although most of the expressions derived from similar building stocks, and although the expressions look very similar with regards to their formulation, the results are very different. This will be shown in the following chapters.

\subsection{On damping in design codes and estimated quantities from the experiments}

Eurocode [4] prescribes the value of $5 \%$ for damping to be used in the design of buildings. In literature, damping value depends on the type of structure, material, and on condition of the structure. For example, it is proposed to use values of damping from 3 to $5 \%$ for concrete structures with considerable cracking, while 7 to $10 \%$ damping should be used for reinforced concrete structures at yield [5], [6]. Early measurements on a real building that vibrated during the San Fernando earthquake in the early 1970's confirmed high damping values ranging from 6,4 to $7,0 \%$ [6]. However, literature overview pointed out that the value of $2 \%$ is also used in numerical modeling of a dynamically loaded reinforced concrete structure exhibiting plastic deformations [13]. It is clear that not all of the reinforced concrete structures can have the same damping because of differences in geometry, different frame infill, etc. Thus, it is prudent to derive expressions for estimating damping in a function of other structural properties. An earlier study [10] promoted expressions for estimating damping in function of the resonant period and geometry related to the building:

$$
\begin{gathered}
\xi=0,72 \cdot T_{1}+\frac{0,70}{T_{1}}, \\
\xi=\frac{1,4}{T_{1}}+47000 \cdot \frac{x}{H}-0,18, \\
\xi=e^{-0,22+\frac{0,42}{T_{1}}}
\end{gathered}
$$

where $T_{1}$ is a resonant period, $x$ is measured displacement at the top of the building, and $H$ is the height of the building. However, it is highlighted [10] that expression (12) is valid only for structures with periods ranging between 0,125 and 1,7 s.

\section{The case study: experimentally tested frame}

A 3D low ductility reinforced concrete frame (Fig. 1) was experimentally tested as part of the 15th World Conference on Earthquake Engineering that took place in Lisbon, Portugal [14]-[16].

The frame, for which many teams from all around the world attempted to predict the inelastic dynamics behavior, was horizontally rattled using shaking table and four input motions of the same frequency content but with increasing nominal intensity levels. The input motions, with regards to the intensity, are referred to later in the paper as low, medium, referent, and high. The selected results obtained from this experiment were provided to the contestants after the conference ended. Specifically, the Osijek's team acquired displacement time histories for both $\mathrm{x}$ and $\mathrm{y}$ direction recorded in nodes $\mathrm{A}$ and $\mathrm{B}$ placed on the slab top face, along the column axis (Fig. 3). All information on the frame and the experimental procedure is provided in [14]-[16]. 


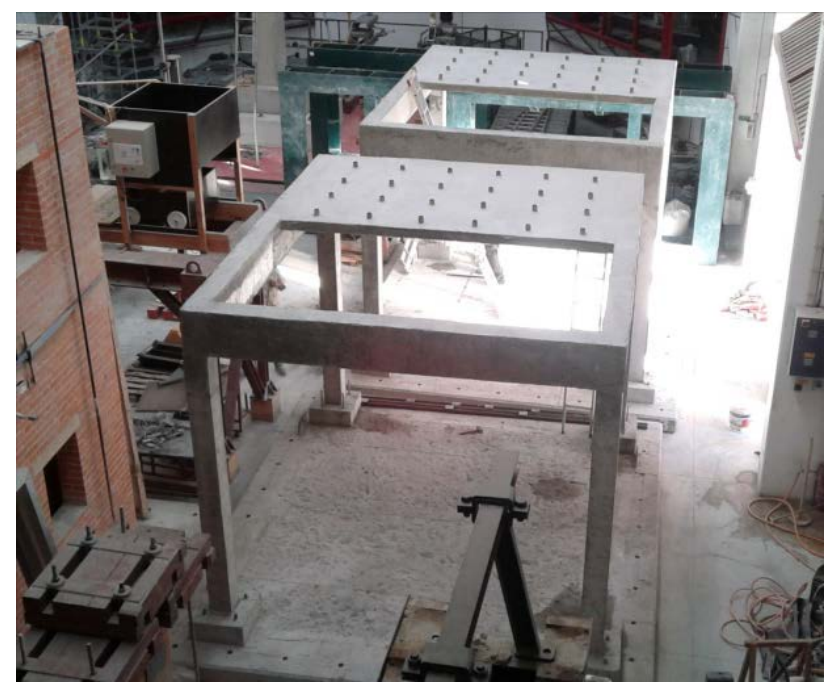

Figure 1. General view of the frame after formwork removal [16].

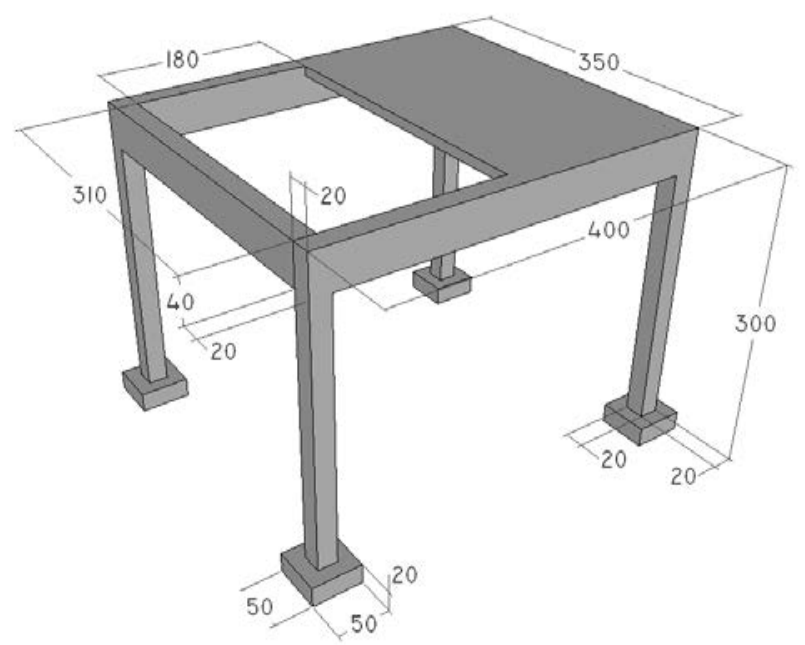

Figure 2. Geometry (in $\mathrm{cm}$ ) of experimentally tested reinforced concrete frame.

\subsection{Frame geometry and experiment setup}

The frame consisted of four reinforced concrete columns $20 / 20 \mathrm{~cm}$ and four beams $20 / 40 \mathrm{~cm}$. The columns were $2,6 \mathrm{~m}$ high, while the ground plan dimensions of the frame were $4 \mathrm{~m}$ North-South and 3,5 m East-West (Fig. 3). Foundations were 50/50 $\mathrm{cm}$ in a horizontal plane and $20 \mathrm{~cm}$ thick, placed under every column (Fig. 2). They were used to attach the model to the shaking table. A $10 \mathrm{~cm}$ thick concrete slab was cast to carry additional dead weight (Fig. 2). The additional load comprises nine groups of dead weight denoted as $1 \mathrm{~T}, 2 \mathrm{~B}, 3 \mathrm{~T}, 4 \mathrm{~B}$, 5T, 6B, 7B, 8B and 9B with a mass of 1126,1134 ,
1122, 1130, 1128, 1138, 1134, 1131 and $1131 \mathrm{~kg}$ respectively. Fig. 2 shows the dead weight numbering system where $\mathrm{T}$ refers to top and $\mathrm{B}$ to the bottom weight. Each dead weight group was fixed to the slab using steel fasteners, leading to an additional mass of approximately $36 \mathrm{~kg}$ per each group. The dimensions of dead weights were $840 / 840 / 250 \mathrm{~mm}$. The modulus of elasticity and specific density of the concrete used to cast the model were experimentally determined equal to $33500 \mathrm{~N} / \mathrm{mm}^{2}$ and $2300 \mathrm{~kg}$ respectively. During the experiment, the frame was simultaneously excited in two perpendicular horizontal directions. No vertical or rotational input motions were introduced to the shaking table. The frame was not retrofitted nor altered between the four input motions. First intensity of the input motion did not cause any visible damage to the frame, and therefore it can be considered that the structure stayed theoretically elastic.

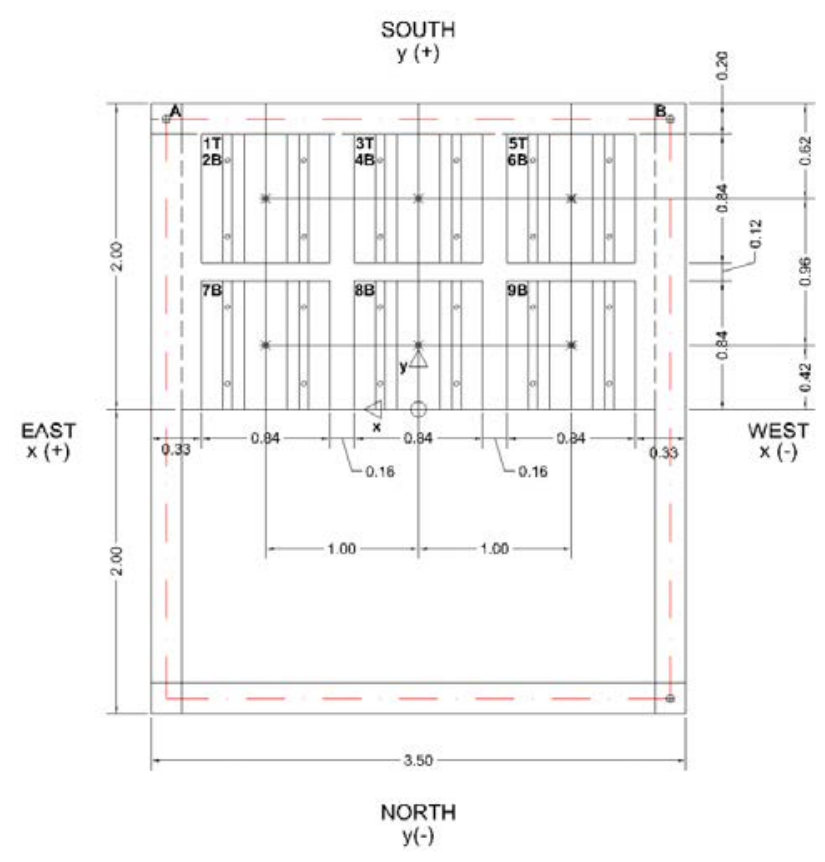

Figure 3. Model dimensions (in $\mathrm{m}$ ) and the disposition of dead weight [16].

\subsection{Filtering and smoothing of time histories}

After the model was tested and the blind test competition winners announced, node displacement time history records were shared among the competitors. Acquired displacement time histories contained high frequency noise, making them difficult to use for determining dynamic properties 
of the frame. To make them useful for further interpretation they needed to be denoised and smoothened. This was done by using the Hanning window approach [17]:

$$
S_{k, \text { new }}=0,25 \cdot S_{k-1}+0,50 \cdot S_{k}+0,25 \cdot S_{k+1}
$$

where $S_{\mathrm{k}}$ is displacement value for a specific moment. The use of this approach does not artificially reduce the energy of the recorded time histories [17]. In this work the procedure was repeated fifty times over the same time history data. However, the literature shows that the same procedure can be repeated over the same recorded data up to one hundred times (e.g. [17], [18]). For the sake of illustration, Fig. 4 provides a comparison of original and smoothed displacement time histories. The displacement time history records were available only for the time during which the input motion was introduced to the shaking table. The free vibrations of the tested structures were not available for analysis. Consequently, it was assumed that the structure is oscillating freely when the artificial input shaking signal diminishes.

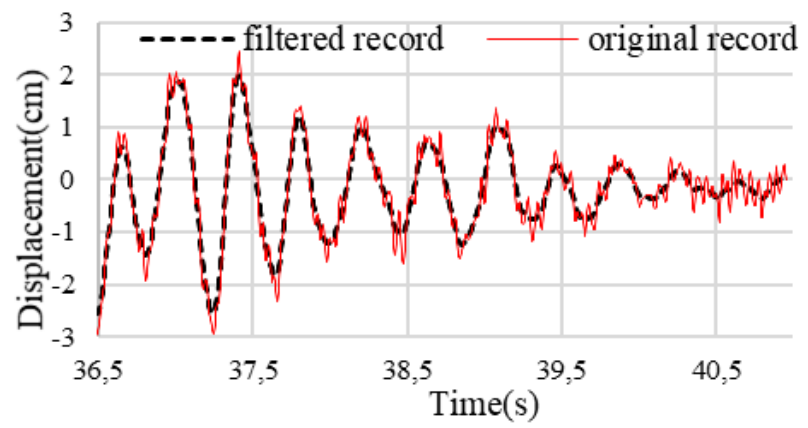

Figure 4. Comparison of original with filtered displacement time history.

Further, since the upper part of the model comprises most of its mass and because the significant amount of the mass was excited with a large amount of energy prior to the 37th second (Fig. 5), the authors assume that until the end of the induced shaking structure oscillates pseudo-freely. Recent research [10] outlined that the fundamental period and damping obtained from ambient vibrations are consistent with counterparts calculated from data recorded during forced vibrations of low intensities. Acceleration record for input signal simulating earthquake is provided in Fig. 5.

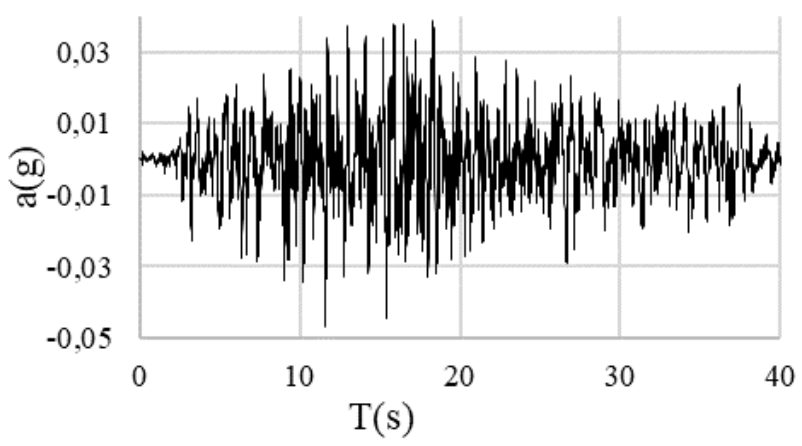

Figure 5. The input signal to the shaking table simulating an earthquake.

\section{Comparison of fundamental periods and damping predicted for 15WCEE building}

This chapter provides a comparison of analytically, numerically, and experimentally obtained fundamental periods and damping based on information and data available from the experiment conducted in a laboratory in Portugal.

\subsection{Experimentally obtained dynamic properties}

After smoothing of all available experimentally obtained records, expressions (14) and (15) [6] were used to determine the fundamental period and damping of structure respectively. Because most of the mass of the reinforced concrete model was concentrated above its columns, we can think of it as a single degree of freedom system. This allows us to use the following expressions to determine the damping and resonant period [5], [6], [10]:

$$
\begin{gathered}
\xi=\frac{1}{2 \pi j} \ln \frac{u_{i}}{u_{i+j}} \\
T_{1}=\frac{t_{i+j}-t_{i}}{j}
\end{gathered}
$$

where $j$ is the number of waves between the observed nodes, $u_{\mathrm{i}}$ is displacement at the beginning of observation, $u_{i+j}$ is displacement at the end. Following, $t_{i}$ is considered to be time value noted at the beginning and $t_{i+j}$ at the end. Fig. 6 shows an example of a smoothed signal and adds information on how expressions (14) and (15) were used for determination of fundamental period and damping. 


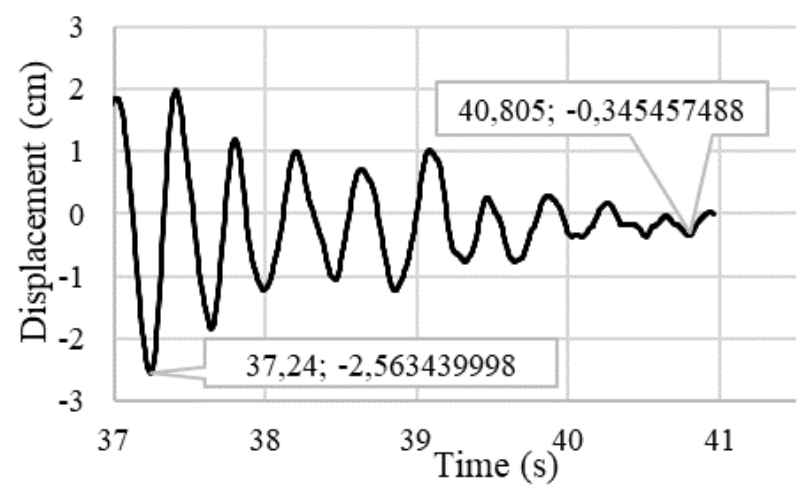

Figure 6. Record of free movements of the structure.

Two points on the displacement time history were selected between which displacement was continually decreasing. Because the selection of the points on time history record is subjective it can have an impact on the final results. Using nodes values shown in Fig. 6 and expressions (14) and (15) period of $0,395 \mathrm{~s}$ and damping of 3,5\% were obtained respectively. This procedure was repeated for both nodes on structure (A and B) for both directions ( $\mathrm{x}$ and $\mathrm{y}$ ), but also for all four input motions in shaking table. The results are provided in Fig. 7 and Fig. 8. In Fig. 7 it is possible to determine elongation of the fundamental period of the model as the damage is accumulating. This is consistent with findings in [7] and [10].

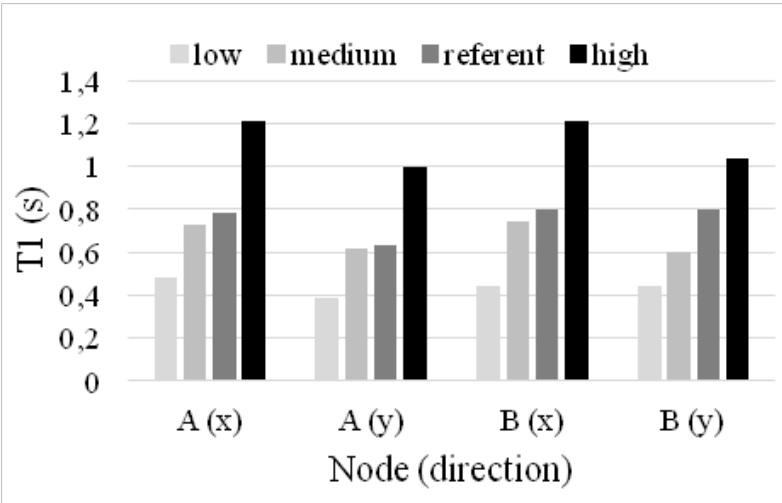

Figure 7. Fundamental period of oscillation after each of the four shakings.

Fundamental period of oscillation estimated from the low intensity motion is representative for elastic structure, while other calculated values are affected by the formation of cracks and plastic regions in structural elements. As the damage was accumulating and the model became softer the fundamental period of oscillation was increasing.

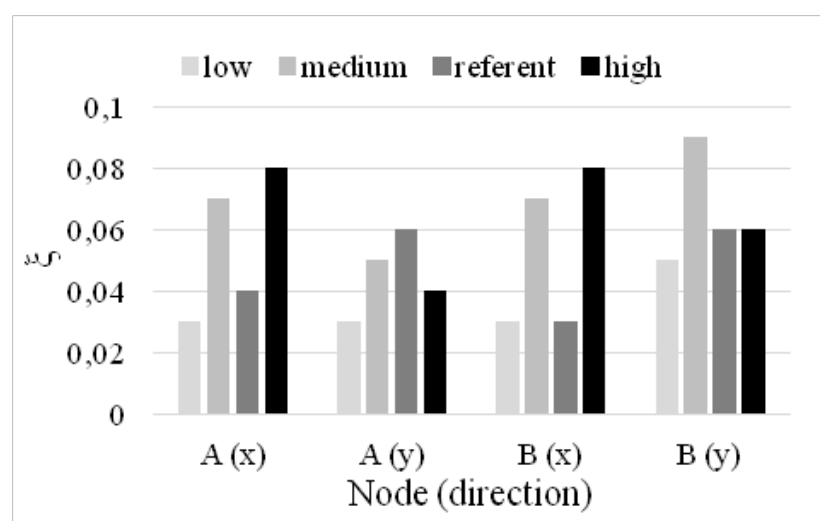

Figure 8. Damping after each of the four shakings.

The value of the fundamental period was close to $0,4 \mathrm{~s}$ for the intact model. At the end of the test with input motion of the highest intensity, the period increased to a value of $1,1 \mathrm{~s}$. The change in damping of the structure was also observed. Figure 8 shows the damping values obtained from the experimentally obtained data. Although Fig. 8 does not show as clear trends as Fig. 7, it can be argued that damping also increases as the damage is being accumulated. For instance, if referent readings for $\mathrm{x}$ direction of A and B nodes are omitted from Fig. 8, the trend of increase in damping can be recognized. Even though it was expected that damping would change in the same manner as period, this was not the case. Although the model was damaged progressively it was not always exhibiting the same level of damping for the same level of input motion intensity. Progressive accumulation of damage in the model was confirmed through nonlinear dynamic numerical analysis conducted using the software SAP2000 [19]. However, if the average values are calculated for each of the four input motion intensities, there is a clear trend of damping increase with damage accumulated. Scatter of damping values can be explained through inadequate input data since the displacement records used for calculation are pseudo-free and due to the subjective selection of the nodes on time history graphs. Nonetheless, damping values obtained from experimental results are excellent agreement with recommendations provided in [5] and [6]. 


\subsection{Analytically and numerically obtained dynamic properties}

This chapter discusses the fundamental periods obtained using expressions described earlier in this paper. The expressions used are here summarised in Table 1 along with corresponding results.

Table 1. Fundamental periods according to different authors and approaches.

\begin{tabular}{|c|c|c|}
\hline ID & Expression & $T_{1}(\mathrm{~s})$ \\
\hline 1 & $0,075 \cdot H^{0,75}$ & 0,179 \\
\hline 2 & $0,026 \cdot H^{0,9}$ & 0,074 \\
\hline 3 & $0,016 \cdot H$ & 0,051 \\
\hline 4 & $0,0466 \cdot H^{0,9}$ & 0,132 \\
\hline 5 & $0,0294 \cdot H^{0,804}$ & 0,075 \\
\hline 6 & $N / 10$ & 0,100 \\
\hline 7 & $N / 24$ & 0,042 \\
\hline 8 & $2 \cdot \pi \cdot \sqrt{\frac{m}{k}}$ & 0,520 \\
\hline 9 & Numerically & 0,303 \\
\hline 10 & Experimentally & $0,415^{*}$ \\
\hline * average from experimental data for y direction \\
\hline \multicolumn{2}{|c|}{}
\end{tabular}

Table 1 provides also numerically calculated fundamental period using software SAP2000 [19] and an average value of period calculated from data recorded in nodes A and B for direction y during the low intensity test. All results are also shown in Fig. 9 for easier examination. As shown in Table 1 and illustrated in Fig. 9, the fundamental period varies a lot. The first assumption can be that for one story height building some expressions cannot be used, the second one is that most of the expressions are empirical, and therefore they have the best match for real buildings with infill for particular areas where the data was obtained from. The explanation for the high discrepancy between periods obtained experimentally and periods calculated using analytical expressions was also found in the recent study [10] where its authors highlighted that period obtained from strong vibration data can be up to 30 $\%$ higher when compared to those obtained from ambient vibration data.

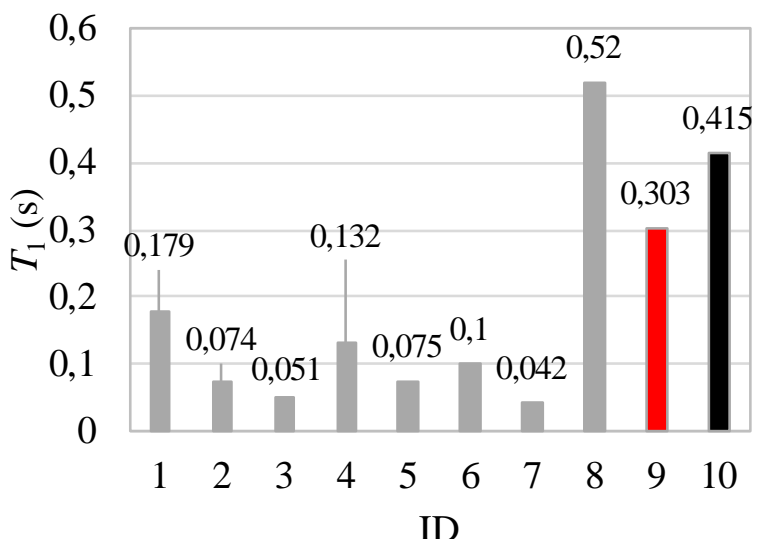

Figure 9. Fundamental period of oscillation according to different authors.

Figure 10 illustrates damping values calculated using expressions (10) and (12) and using fundamental periods listed in Table 1.

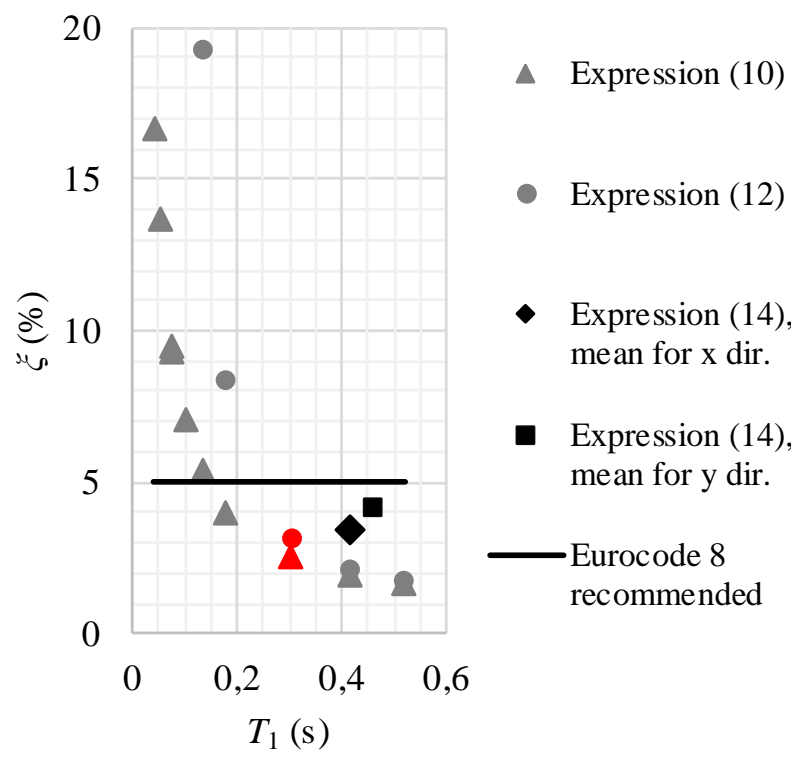

Figure 10. Damping according to different authors.

Also, Fig. 10 shows the mean value of damping calculated using the expression (14) based on the experimental data from the low intensity test. Initial damping for $\mathrm{x}$ and $\mathrm{y}$ direction calculated based on the experimentally obtained data is 3,5\% and 4,25 $\%$ respectively. From the results obtained it is clear that damping is overestimated for almost all analytically predicted fundamental periods lower than $0,2 \mathrm{~s}$, when compared to the value recommended in Eurocode 8 and calculated based on experimentally and numerically obtained data. For easier referencing between Fig. 9 and 10 
numerically and experimentally obtained data is marked in red and black respectively.

Damping calculated using diminishing pseudo-free vibrations is in good agreement with values recommended in Eurocode 8.

\section{Conclusion}

A 3D low ductility reinforced concrete frame was experimentally tested as part of the 15th World Conference on Earthquake Engineering that took place in Lisbon, Portugal. The frame was tested using a shaking table and four horizontal input motions of the same frequency content but with increasing nominal intensity levels. Between the four input motions, the frame was not repaired. This allowed challenging the hypothesis that fundamental period and damping can reliably be determined from data recorded on damaged building subjected to diminishing pseudo-free vibrations that diminish. Dynamic properties of the experimentally tested frame were derived after each of the four motions. Using the experimentally obtained data it was possible to determine elongation of the fundamental period of the model as the damage is accumulating and as the model becomes softer. The damaged model after the four tests had three times longer period when compared to the intact model. Likewise, the study showed that damping also increases as the damage is being accumulated in the building being tested. After four tests conducted it was observed that damping increases between two to four times when compared to the value of damping of the intact model. Moreover, it was noted that all damping values calculated using the four pseudo-free input motions well agree with recommendations provided in Eurocode 8 and literature studied. However, this research showed that damping calculated using the analytical expressions based on the analytically predicted fundamental periods overestimate experimentally obtained damping for eight of nine periods estimated lower than 0,2 s. Nonetheless, personal experience and judgment on fundamental period and damping calculated using analytical expressions should always be used. In other words, if analytically obtained period well describes the structure in consideration and analytically calculated damping based on that period is within the reasonable range regarding the recommended damping values prescribed in literature or norms. then this pair of dynamic properties well describes the structure in consideration. This step-in numerical modeling should be used as the crossvalidation of the model validity. However, this should be further tested on other experimentally based data. Comparisons between analytically, experimentally, and numerically obtained results showed scattering especially when empirical expressions depending on few structural properties were used. On the other hand, dynamic properties calculated using pseudo-free vibrations and gained through numerical modeling showed complementary results. It is concluded that empirically based analytical expressions provide more reliable results when used in areas for which research data was collected. Average damping determined for four dynamic loadings of different intensity was increasing with mild scatter of results due to the uncertainty of input data and subjectivity impact. Although the results obtained from pseudo-free experimental vibrations are in good agreement with recommendations in literature observed, it is still recommended to use displacement time history records of the free vibrating stage when determining the dynamic properties of structures. In that manner, the results would be much easier to interpret and certain trends would be more pronounced.

\section{Acknowledgment}

The authors are grateful to the organizing committee of the 15th World Conference on Earthquake Engineering for the experimental data provided. This work was carried out as part of the internal project PENDULARUM and supported by Grant No. 15-04 by the Faculty of Civil Engineering Osijek.

\section{References}

[1] Hadzima-Nyarko, M. et al.: Comparison of fundamental periods of reinforced shear wall dominant building models with empirical expressions, Technical Gazette, 22 (2015), 3, 658-694.

[2] Zhang, D., Tao, Z., Zhang, L.: Research on the deformation behavior of reinforced concrete composite shear walls with concealed bracings 
based on performance, Engineering Review, 37 (2017), 2, 111-121.

[3] Draganić, H., Hadzima-Nyarko, M., Morić, D.: Comparison of $R C$ frames periods with the empiric expressions given in Eurocode 8, Technical Gazette, 17 (2010), 1, 93-100.

[4] EN 1998-1: Eurocode 8: Design of structures for earthquake resistance - Part 1: General rules, seismic actions and rules for buildings, European Committee for Standardization, Brussels, 2004.

[5] Čaušević, M.: Dinamika konstrukcija: potresno inženjerstvo, aerodinamika, konstrukcijske euronorme. Golden marketing - Tehnička knjiga, Zagreb, 2010. (in Croatian)

[6] Chopra, A. K.: Dynamics of structures, Third Edition, Pearson Education, 2007.

[7] Okamoto, S. et al.: U.S.-Japan Cooperative research on $R / C$ full scale building test. Part 2: Damage aspects and response properties before repair works, Proceedings of the 8 Word Conference on Earthquake Engineering, San Francisco, 1984, 8.

[8] Chiauzzi L. et al.: Estimate of fundamental period of reinforced concrete buildings: code provisions vs. experimental measures in Victoria and Vancouver (BC, Canada), Proceedings of the 15th World Conference on Earthquake Engineering, Lisbon, 2015, 10.

[9] Crowley, H., Pinho, R.: Period-height relationship for existing European reinforced concrete buildings, Journal of Earthquake Engineering, 8 (2004), S1, 93-119.
[10] Salameh, C. et al.: Seismic response of Beirut (Lebanon) buildings: instrumental results from ambient vibration, Bulletin of Earthquake Engineering, 14 (2016), 10, 2705-2730.

[11] Gallipoli, M.R. et al.: Empirical estimates of dynamic parameters on a large set of European buildings, Bulletin of Earthquake Engineering, 8 (2010), 3, 593-607.

[12] Guler, K., Yuksel, E., Kocak, A.: Estimation of the Fundamental Vibration Period of Existing $R C$ Buildings in Turkey Period of Existing RC Buildings in Turkey Utilizing Ambient Vibration Record, Journal of Earthquake Engineering, 12 (2008), S2, 140-150.

[13] Chen, Y.S., Wu, B., Pan, T.L.: A novel sectional constitutive model for beam-column element, Engineering Review, 36 (2016), 1, 4152.

[14] 15WCEE Blind Test Challenge - Design report, 2012.

[15] 15WCEE Blind Test Challenge - Preliminary Test report, 2012.

[16] [15WCEE Blind Test Challenge - Material Data and Construction report, 2012.

[17] Towhata, I.: Geotechnical Earthquake Engineering, Springer, Verlag Berlin Heidelberg, 2008.

[18] Kraus, I.: Spektri potresnog odziva plitko temeljenih konstrukcija na mekim tlima, $\mathrm{PhD}$ thesis, Faculty of civil angineering Osijek, University of J.J. Strossmayer Osijek, Croatia, 2014. (in Croatian)

[19] CSI (Computers and Structures, Inc.): SAP2000, structural analysis program, version 18.1.0. Berkeley, California, USA, 2016. 